\title{
CORRECTION
}

\section{Correction to: TOSCA: a Tool for Optimisation in Structural and Civil engineering Analyses}

\author{
Corrado Chisari $^{1}$ (1) $\cdot$ Claudio Amadio $^{2}$
}

Published online: 18 December 2018

(c) The Author(s) 2018. This article is an open access publication

\section{Correction to: International Journal of Advanced Structural Engineering \\ https://doi.org/10.1007/s40091-018-0205-1}

With the aim of avoiding confusion with any other commercial software having the same name, any future reference to the optimisation software package described in this article should be made as TOSCA-TS.
Publisher's Note Springer Nature remains neutral with regard to jurisdictional claims in published maps and institutional affiliations.

Open Access This article is distributed under the terms of the Creative Commons Attribution 4.0 International License (http://creativecommons.org/licenses/by/4.0/), which permits unrestricted use, distribution, and reproduction in any medium, provided you give appropriate credit to the original author(s) and the source, provide a link to the Creative Commons license, and indicate if changes were made.

Corrado Chisari

c.chisari12@imperial.ac.uk

Claudio Amadio

amadio@univ.trieste.it

1 Department of Civil and Environmental Engineering, Imperial College London, South Kensington Campus, London SW7 2AZ, UK

2 Department of Engineering and Architecture, University of Trieste, Piazzale Europa, 1, 34127 Trieste, Italy 